\title{
PERFORMANCE ANALYSIS OF VARIOUS PARAMETERS BY COMPARISON OF CONVENTIONAL PITCH ANGLE CONTROLLER WITH FUZZY LOGIC CONTROLLER
}

\author{
Jay Verma ${ }^{1}$, Yogesh Tiwari ${ }^{2}$, Anup Mishra ${ }^{3}$, Pawan Tapre ${ }^{4}$ \\ ${ }^{1}$ Assistant professor, Electrical Department, SSIET, C.G, India \\ ${ }^{2}$ Associate Professor, Electrical Department, SSCET, C.G, India \\ ${ }^{3}$ Professor, Electrical Department, BIT, C.G, India \\ ${ }^{4}$ Associate Professor, Electrical Department, SSCET, C.G, India
}

\begin{abstract}
This paper deals with a variable speed wind turbine coupled with a permanent magnet synchronous generator connected through a two mass drive train. This drive train is connected to synchronous generator and after the conversion process finally connected to grid and the idea of transmission over a long distance makes the use of converter necessary and at the receiving end. The inverter is used to convert it back and the inverter is designed with a proper gate signal to get the best output three phase voltages. The fuzzy logic controller is used to track generator speed with varying wind speed to optimize turbine aerodynamic efficiency in the outer speed loop. Pitch angle control of wind turbine has been used widely to reduce torque and output power variation in high rated wind speed areas. The machine side converter is designed to extract maximum power from the wind. In this work a WECS connected with grid is designed in Matlab and a Fuzzy controller is designed to improve the output and we can see the major difference in DC link voltage and reactive power in transmission line. From the outputs we can also go through the reactive power issue which system is best for inductive load or capacitive load. The simple PI system is good for capacitive load and the fuzzy system is better option for the inductive load. The results of both the system of normal controller and fuzzy controller is compared and analyzed.
\end{abstract}

Key Words: Fuzzy logic controller (FLC), permanent magnet synchronous generator (PMSG), insulated gate bipolar transistor (IGBT), Pulse width modulation (PWM), Wind energy conversion system, DC link capacitor. FACTS Flexible A.C Transmission system, PI proportional integral

\section{INTRODUCTION}

Now days the use of electricity is the basic needs of any firm it may be for industrial purpose or for simple household the first and foremost requirement of all is the electric energy for $24 \mathrm{x}$ 7.

To fulfill this requirement all the nations rather it is developed country or developing country trying to provide it is as well as possible. In this race of production of electric energy the coal and fuel based plants are the best options since their efficiency is well good as compared to other generating systems. But as we all know the fossil fuels are non renewable so we have to take care of that portion also and the main thing is the adverse effects of these generating stations .As so much harmful gases are exhausted in environment which will effect environment and also become a reason of increased global warming.

To overcome all these effects a step has been taken of producing electric energy by using non renewable energy resources such as solar power and wind power. In these systems the electric energy generated is clean and pollution free. The installation of wind turbines in power systems has developed rapidly in the last 20 years and the national and international growth rates and policies indicate that this development will continue. During 1999, 3920MWof wind turbine capacity was installed in the world, making up a total accumulated installation of $13932 \mathrm{MW}$ of wind power at the end of 1999 [2].

For the installation of wind energy MNRE scheme (The Ministry of New \& Renewable energy) has introduced to aware more and more people about this technology, government also gives incentives in order to promote wind energy. Wind is air in motion; this is actually derived from solar energy. About $2 \%$ of total solar flux that reaches the earth's surface is transformed into wind energy due to uneven heating of atmosphere. This kinetic energy of wind is used to gain the rotational motion of wind turbine which is coupled with an electrical generator to supply over a region acting as stand alone or supplying power to a grid. An actual WECS 
(Wind energy conversion system) be considered as follow [3] which can be used in two different ways

(A) Isolated stand alone system

(B) Grid connected system

In wind energy application variable speed wind turbines are much better performance due to its maximum power point tracking algorithm (MPPT). Now a days Doubly fed Induction generator are widely used in a variable speed wind turbine but te main drawback is the requirement of gear box to match turbine and rotor speed. The gearbox many times suffers and requires regular maintenance making the system unreliable [3]. The reliability of variable speed wind turbine can be improved significantly using a direct drive based permanent magnet synchronous generator (PMSG).

For obtaining maximum output a control strategy has been developed and the generator side switch mode rectifier has been controlled to achieve maximum power from the wind. This method requires one switching device (IGBT) which is used to control generator torque to extract maximum power.

\subsection{Wind Turbine Characteristics}

Wind turbine modeling: In our proposed work a variable speed wind turbine is connected to a two mass drive train and the output of this drive train is connected to a permanent magnet synchronous generator and then a measurement block is added and the three phase is converted to DC by using simple universal bridge so that we can supply it over a long distance as losses will be less in DC supply and a DC link capacitor is connected so as to maintain a constant DC link voltage over the transmission line it should remain constant over the line since it is necessary for conversion it again in ac voltage by the use of inverter. In this inverter we use IGBT type six pulse so that switching will be very fast and a suitable control system is designed so that maximum torque can be extracted. The output is then given to a variable load and again it is passed through an LC filter and the output of filter is then applied to the grid which is controllable voltage source in our work. All the design is done in matlab.

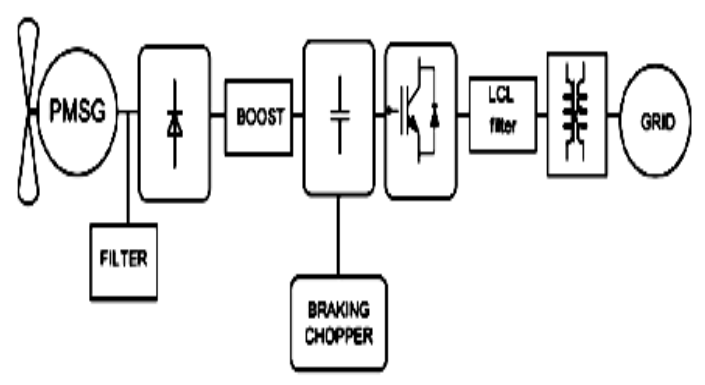

Fig-1: Overall Wind Énergy Conversion System

This block implements a variable pitch wind turbine model. The performance coefficient $\mathrm{Cp}$ of the turbine is the mechanical output power of the turbine divided by wind power and a function of wind speed, rotational speed, and pitch angle (beta). $\mathrm{Cp}$ reaches its maximum value at zero beta. According to the Aerodynamics, the aerodynamic power of the wind turbine can be expressed as

$$
P_{r}=\frac{1}{2} \rho \pi R^{2} C_{p}(\lambda) V^{3}
$$

When the rotor speed is adjusted to maintain its optimal value, the maximum power can be gained as

$$
P_{r \max }=K_{\text {opt }} \omega^{3}
$$

Where $K_{\text {opt }}$ is decided by

$$
\begin{gathered}
K_{\text {opt }}=\rho \pi R C_{p \max ^{2} \lambda^{3}} \ldots \ldots \ldots \\
T_{\text {mopt }}=K_{\text {opt }}\left(\omega_{\text {mopt }}^{2}\right)
\end{gathered}
$$

The mechanical rotor power generated by the turbine as a function of the rotor speed for different wind speed is shown in Fig. 2

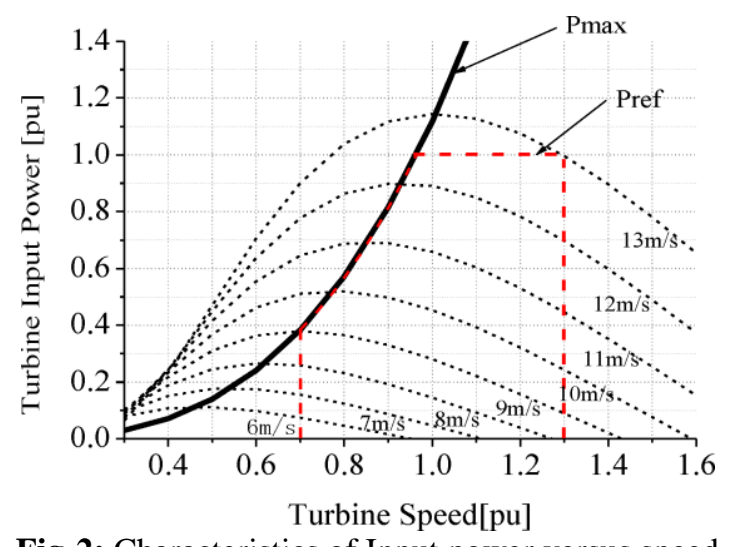

Fig-2: Characteristics of Input power versus speed

\subsection{Two Mass Drive Train}

Here WECS is represented with the two-mass drive train model. The differential equations governing its mechanical dynamics are presented as follows [4]

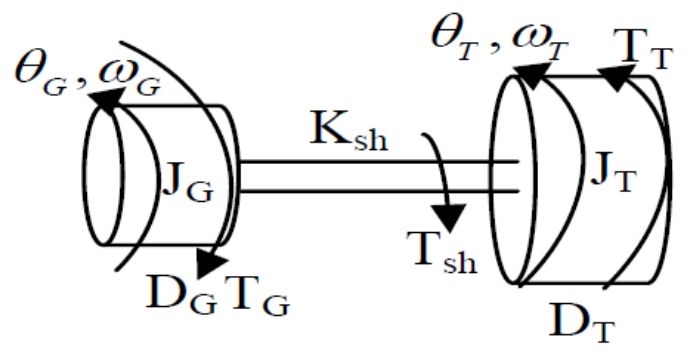

Fig-3 Two mass drive train model 


$$
\begin{gathered}
2 H_{t} \frac{d w t}{d t}=T_{m}-T_{s h} \\
\frac{1}{w_{e l b}} X \frac{d}{d t} \theta_{t w}=w_{t}-w_{r} \\
2 H_{g} \frac{d_{w r}}{d t}=T_{s h}-T_{g}
\end{gathered}
$$

Where $H_{t}$ is the inertia constant of the turbine, $H_{g}$ is the inertia Constant of the PMSG, $\theta_{t w}$ is the shaft twist angle, wt is the Angular speed of the wind turbine in p.u., ${ }^{W_{r}}$ is the rotor speed of the PMSG in p.u., ${ }^{w_{e l b}}$ is the electrical base speed, and the Shaft torque $T_{s h}$ is

$$
T_{s h}=K_{s h} \theta_{t w}+D_{t} \frac{d}{d t} \theta_{t w}
$$

Where $K_{s h}$ is the shaft stiffness and $D_{t}$ is the damping coefficient

\section{CONTROL OF PROPOSED SYSTEM}

In this proposed wind energy system the output ac voltage is controlled through amplitude and frequency. Power from PMSG based wind turbine is fed to ac-dc-ac converters to maintain the output voltage at desired amplitude and frequency. The reactive power and an active power exchange with the grid are function of phase and amplitude of terminal voltage at AC terminals of a GSC. The objective of controlling a GSC is to keep constant DC link voltage under change in generated active power while keeping sinusoidal currents of PMSG as shown in figure 4.

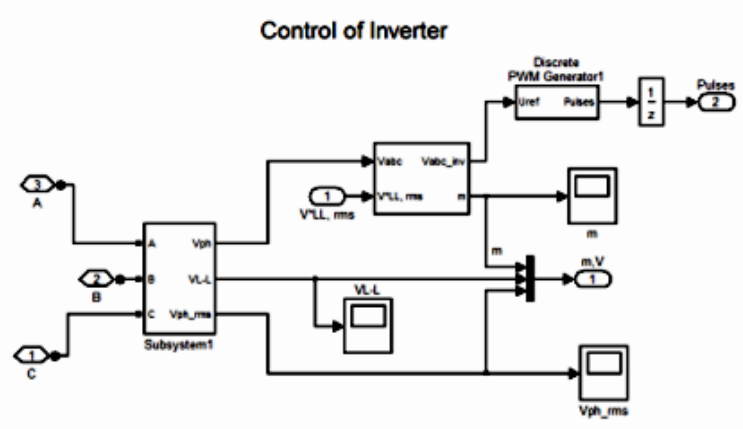

Fig-4: Subsystem of control system of inverter

Due to unbalanced load connected to an inverter the currents will not same in all the phases and hence LC filters will cause unequal voltage drops. Hence it is necessary to compensate voltage imbalance .To achieve this goal the rms value of phase voltages and the reference phase voltage is given to a PI controller. The output of PI controller is multiplied with a unit sine wave generator to get the reference phase voltages. By using these reference voltages PWM pulses are generated to switch the load side inverter. The schematic of this control arrangement is shown in below figure 5. [6]

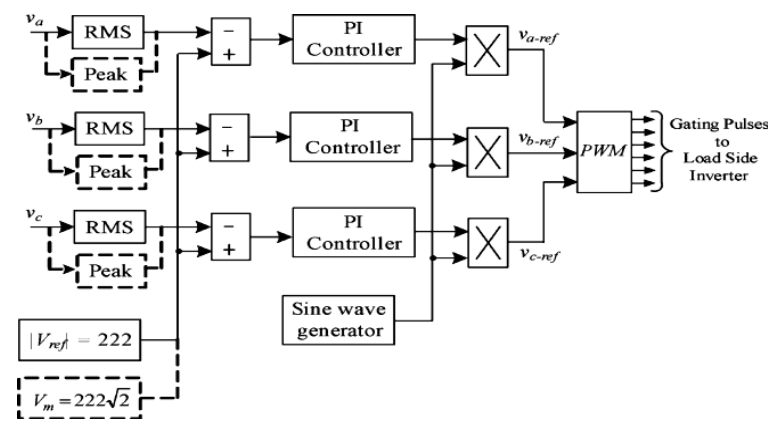

Fig-5: Gate pulse generation of inverter

\section{FUZZY CONTROL SYSTEM}

A fuzzy logic controller may consist of three basic blocks, namely, Fuzzification, Inference system and Defuzification [7]

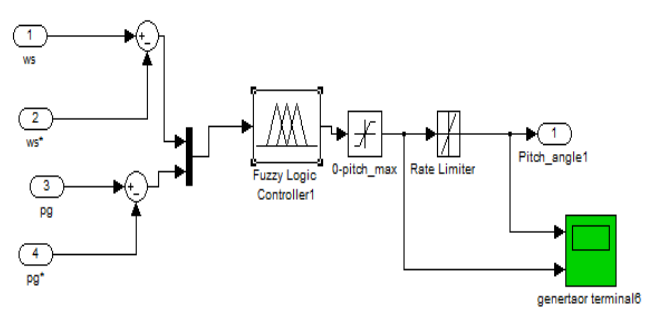

Fig-5: Fuzzy control arrangement

\subsection{Fuzzification}

Fuzzification is the procedures to process the input variables with membership functions and determine the degree to which the input variables are belong to each of the appropriate fuzzy sets via membership functions. Membership functions (MF) are used to convert each value of input variables into a membership value between 0 and 1 . Membership functions may take any Arbitrary shape or form, such as Gaussian distribution curves, Sigmoid curves, bell shape curves, triangular functions or tables. The selection of membership functions is very important as it means a kind of controller tuning. Once the membership function shape has been chosen, the values they are centered about and the width of the functions have to be set. Overlapping of membership functions is required as it means that more than one rule is fired at any time, which is a key feature of fuzzy systems. 
Triangular membership function are used as they are easier to implement and quicker to process. In the proposed fuzzy system, seven fuzzy sets have been considered for each input: negative very big (NVB), negative big (NB), negative medium (NM), negative small (NS) zero (ZE), positive small (PS), positive medium (PM) and positive big (PB), positive very big (PVB). Before fuzzification, the input variables are normalized using base values.

\subsection{Fuzzy Inference System}

The fuzzy inference includes the process of fuzzy logic operation, fizzy rule implication and aggregation. In the fuzzy inference system, the fuzzified input variables are processed with fuzzy operators and the IF-THEN rule implementation. The output fuzzy sets for each rule are then aggregated into a single output fuzzy set. Aggregation is the process by which the fuzzy sets that represent the outputs of each rule are combined into a single fuzzy set. The input of the aggregation process is the list of output fuzzy sets and the output of the aggregation process is one fuzzy set for each output variable.

\subsection{Defuzzification}

The input for the defuzzification process is a fuzzy set (the aggregate output fuzzy set) and the output is a single value. The centroid method is used for defuzzification; it returns the centre of the area under the curve representing the aggregated output fuzzy set.

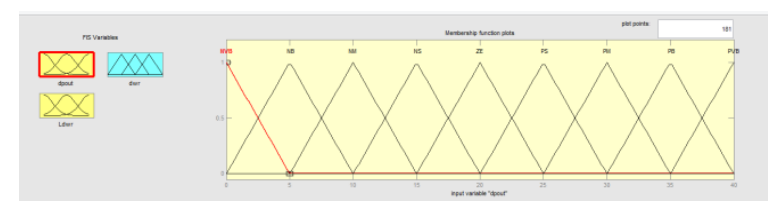

Fig-6: Membership function ${ }^{d}$ pout

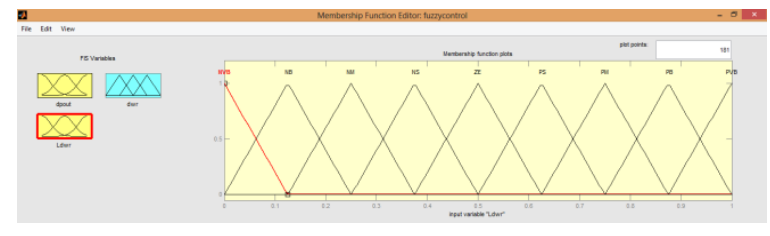

Fig-7: Membership function ${ }^{L_{\text {dwr }}}$

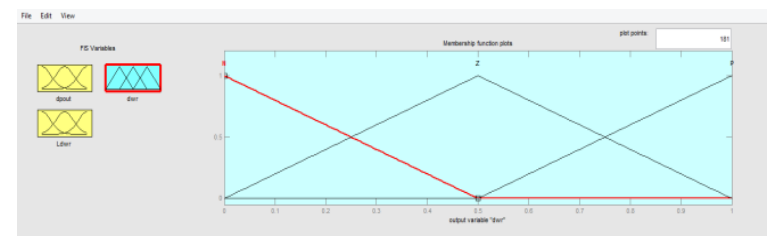

Fig-8: Output membership function $d_{w r}$

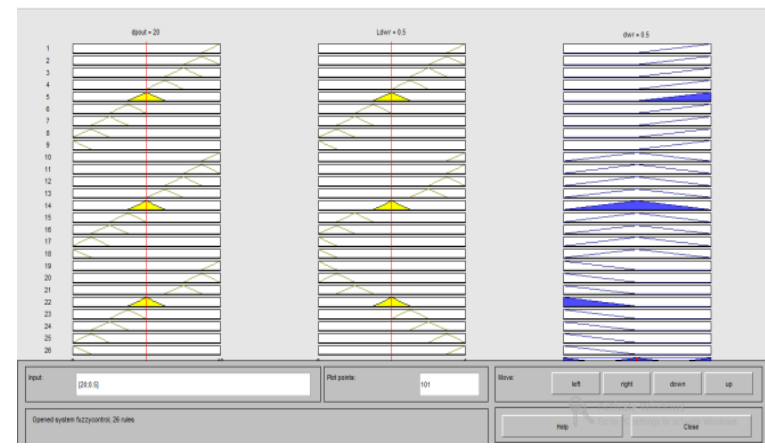

Fig-9: Rule view of the next fuzzy control system

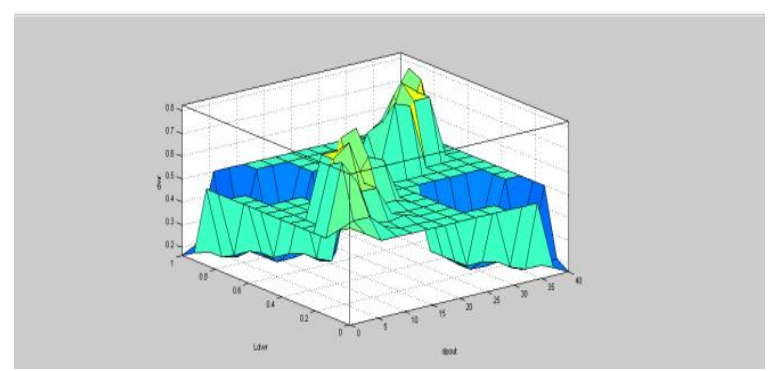

Fig-10 surface view of the next fuzzy control system

4. OVERALL DESIGN OF PROPOSED WIND

\section{ENERGY CONVERSION SYSTEM}

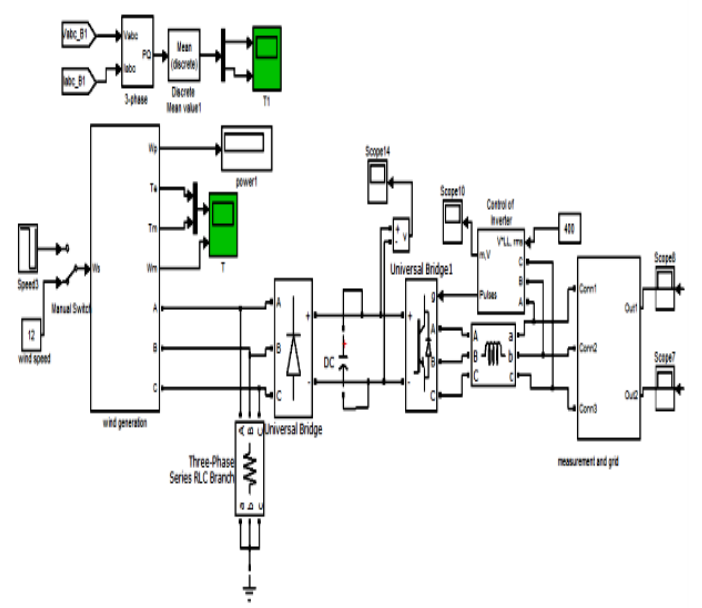

Fig-11: Proposed wind energy conversion system in Matlab

Table-1: Parameters of turbine generator system

\begin{tabular}{|l|l|}
\hline Wind Turbine Parameters & Values \\
\hline Density of air & $1.225 \mathrm{Kg} / \mathrm{m} 3$ \\
\hline Area swept by blades , A & $1.06 \mathrm{~m} 2$ \\
\hline Base wind speed & $12 \mathrm{~m} / \mathrm{s}$ \\
\hline
\end{tabular}


Table-2: Permanent magnet synchronous generator

\begin{tabular}{|l|l|}
\hline PMSG & Values \\
\hline No of poles & 10 \\
\hline Rated speed & $153 \mathrm{rad} / \mathrm{s}$ \\
\hline Rated current & $12 \mathrm{amp}$ \\
\hline Armature resistance & $0.425 \Omega$ \\
\hline Magnetic flux linkage & $0.433 \mathrm{wb}$ \\
\hline Stator inductance & $4 \mathrm{mH}$ \\
\hline Rated torque & $40 \mathrm{Nm}$ \\
\hline
\end{tabular}

\section{RESULTS}

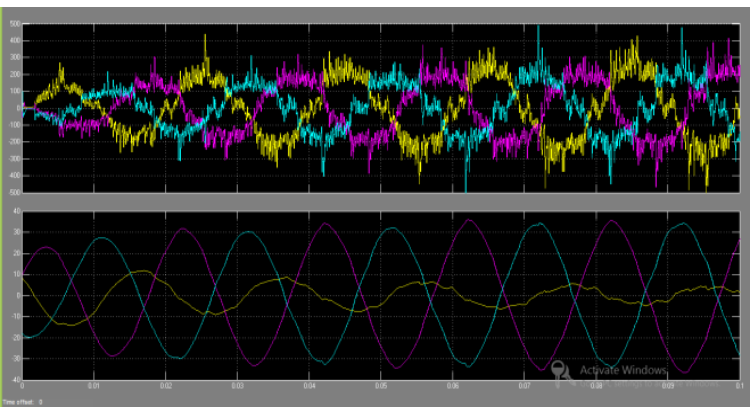

Fig-12: Voltage and current waveform at grid

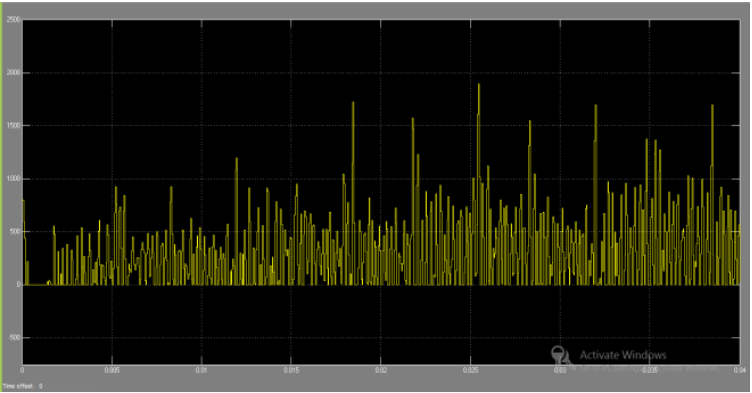

Fig-13: DC link voltage

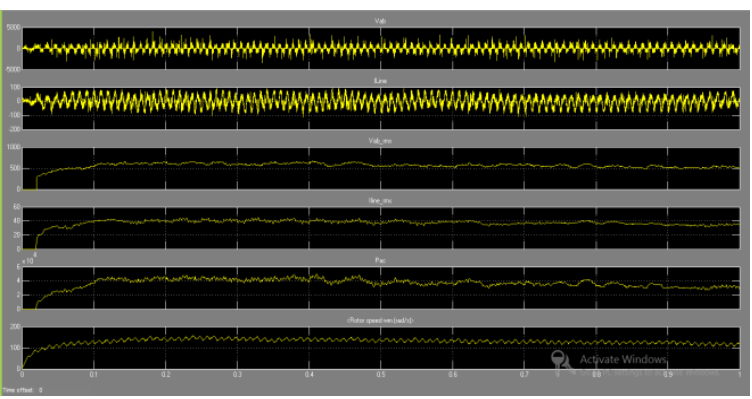

Fig-14: (a) phase voltage (b) line current (c) rms phase voltage (d) rms line current (e) active power (f) rotor speed

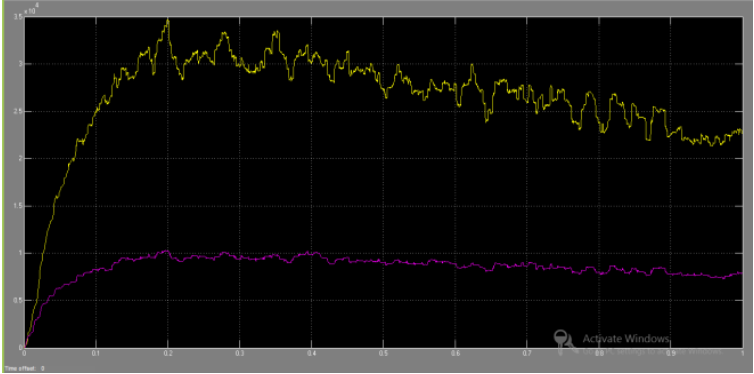

Fig-15: Rms value of active and reactive power

\subsection{Fuzzy Control System Output}

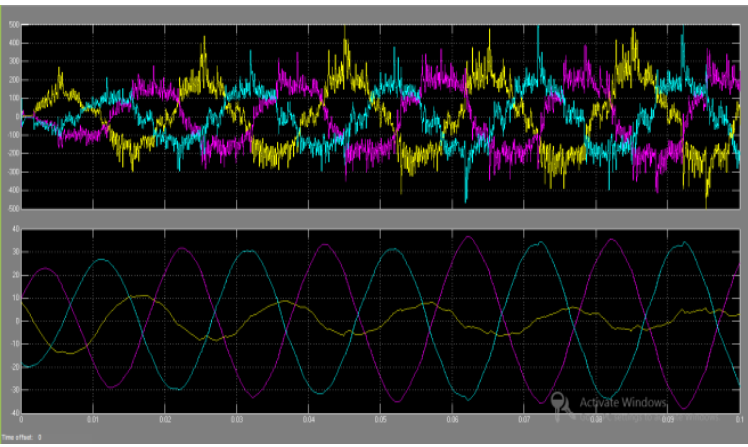

Fig-16: output voltage and current

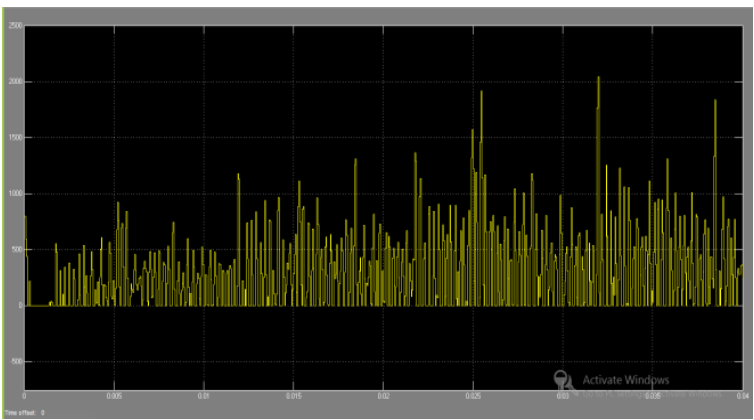

Fig-17: DC link voltage

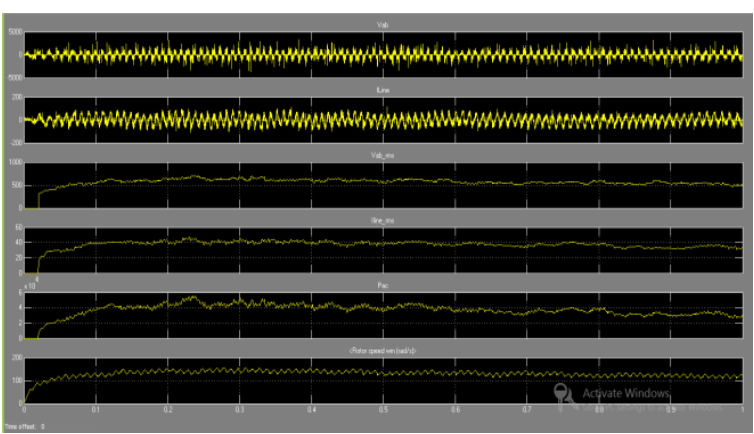

Fig-18: (a) phase voltage (b) line current (c) rms phase voltage (d) rms line current (e) active power (f) rotor speed 


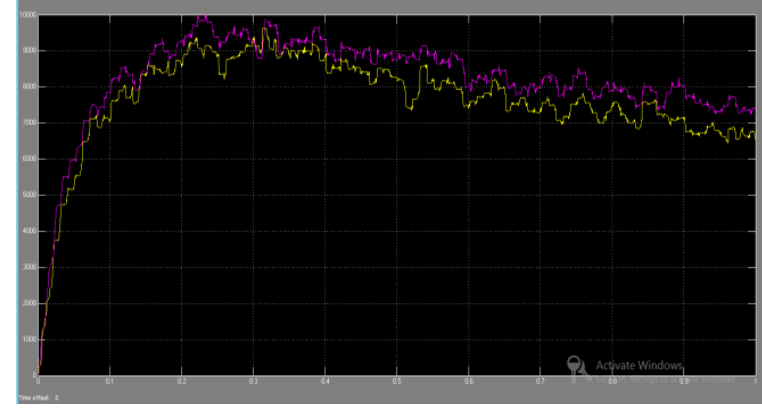

Fig-19: Rms value of active and reactive power

\section{CONCLUSIONS}

After modeling of WECS has been done the outputs has been recorded and shown in the figures above and we can see that we are much closer to the desired output and the main aim is to maintain a DC link voltage constant is also been done with the help of inverter control system and so that the inverter can convert this voltage into three phase voltage.

In the next stage of our work we have developed a control system based on fuzzy system of Mamdani type. In this control system we use different parameters as input like generated power and compare it with reference power and the actual wind speed and reference wind speed is proceeded in this fuzzy control system and the rules are designed on the basis of if - then rules which is shown in above figure. After developing rules and implementing it to the model we can run this model and analyze the results.

We conclude that the DC link voltages are more constant from the fuzzy control system and active and reactive power rms values are also much better shape so that the reactive power compensation is not very big issue in the fuzzy based control system.

The active and reactive power waveforms shows that inn simple pitch control system the reactive power is slightly lower as compared to fuzzy logic controller.We can say that the use of systems depends upon the type of load .The pitch control arrangement using PI controller is much better for capacitive load as well as our next system by the use of fuzzy controller is well good for inductive load since we don't need the reactive power generation. As in many system several FACTS devices are used for the generation or compensation of reactive power.

\section{ACKNOWLEDGEMENTS}

The authors are grateful to Shri I .P .Mishra, President, Shri Shankaracharya group of institution SSGI Dr Deepak Sharma, Director ,Shri shankaracharya institute of engineering and technology SSIET, for their valuable support in our research work.

\section{REFERENCES}

[1]. Staffan Jacobsson IMIT and Department of Industrial Dynamics, Chalmers University of Technology, Gothenburg, Sweden Anna Bergek IMIT and Department of Management and Economics, Linköping University, Linköping, Sweden "International wind energy development-World market update 1999," BTM Consults Aps., Ringkobing, Denmark, 2000.

[2]. Suman Nath, Somnath Rana The Modeling and Simulation of Wind Energy Based Power System using MATLAB. International journal of power system Operation and Energy Management, ISSN (PRINT): 2231-4407, Volume -1, Issue-2, 2011.

[3]. H.Polinder, F .F .A. van der pijl, G.J. de Vilder, and P.J. Tavner, "Comparison of Direct Drive and geared generator concepts for wind turbines,"IEEE Trans.Energy Convers., vol.21, no3, pp.725- 733,sep 2006.

[4]. Kenneth.E.Okedu " Effects of drive train model parameters on a variable speed wind turbine." International journal of renewable energy research, vol 2 , no $2,2012$.

[5]. Jay Verma, Yogesh Tiwari, Anup Mishra, Nirbhay Singh International Journal of Recent Technology and Engineering (IJRTE) ISSN: 2277-3878, Volume-2, Issue-6, January 2014 33 Published By: Blue Eyes Intelligence Engineering \& Sciences Publication Pvt. Ltd. Performance, Analysis and Simulation of Wind Energy Conversion System Connected With Grid.

[6]. C. N. Bhende, S. Mishra, Senior Member, IEEE, and Siva Ganesh Malla "Permanent Magnet Synchronous GeneratorBased Standalone Wind Energy Supply System "IEEE TRANSACTIONS ON SUSTAINABLE ENERGY, VOL. 2, NO. 4, OCTOBER 2011

[7]. Ms. Epsita Pal, Mr. Yogesh Tiwari, Dr. Anup Mishra Variable Speed Wind Power Generation System Based on Fuzzy Logic Control for Maximum Output Power Tracking International Journal of Engineering Research \& Technology (IJERT) Vol. 3 Issue 1, January - 2014 ISSN: 2278-0181

\section{BIOGRAPHIES}

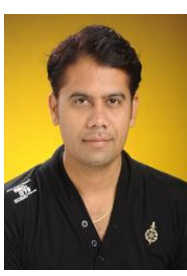

Jay Verma currently pursuing Master of engineering in power system engineering from SSCET.Research interest are in power system and renewable sources of energy. At present working as a Assistant professor in shri shankaracharya institute of engineering and technology, Durg.

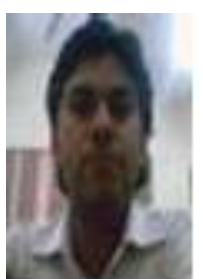

Yogesh Tiwari is currently working as an Asso. Prof. in EEE Department of SSCET Bhilai. He has over 4 year industrial \& 10 year teaching experience. He has published near 15 research papers in national \& international conferences \& journals. 


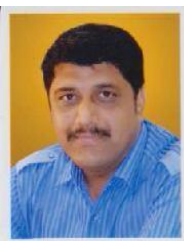

Dr. Anup mishra received his $\mathrm{Ph} . \mathrm{D}$ degree in 2010 from BUIT, Bhopal, teaching and research experience of more than 13 years. He has published more than 10 Research papers in reputed International Journals \& Conferences .At present, he is working as professor and H.O.D. in Electrical and Electronics Department of BIT, (Durg)

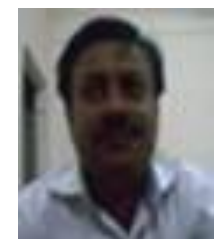

Pawan Tapre is currently working as senior associate professor in EEE department of SSCET. He has teaching experience of 9 years and 4 years industrial experience. He has published more than 10 research papers in reputed international journals and

conferences. 